\title{
Multiphoton Ionization Mass Spectrometric (MPIMS) Study of Phenol: Mechanism of Ionic Fragment Formation $\dagger$
}

\author{
R. S. PANDOLFI, $\ddagger$ D. A. GOBELI, JONATHAN LURIE§ and \\ M. A. EL-SAYED
}

Department of Chemistry, University of California, Los Angeles, California 90024

Time of flight (TOF) mass spectrometry is used in conjunction with a variable repelling voltage technique to elucidate the mechanism by which phenol ionizes and dissociates under $266 \mathrm{~nm}$ pulsed laser irradiation in combination with a $532 \mathrm{~nm}$ or $355 \mathrm{~nm}$ pulsed laser. The results suggest that, like benzene, the molecular ion is the predominant precursor of all ionic species generated in the process. Predominance of $\mathrm{C}_{5} \mathrm{H}_{X}^{+}$species at relatively low powers confirms the presence of a low energy dissociation channel involving the elimination of $\mathrm{CO}$. The use of a second laser at $532 \mathrm{~nm}$ is found to selectively destroy the $\mathrm{C}_{5} \mathrm{H}_{X}^{+}$(as compared to the parent ion) species. The parent ion is found to be protected from the radiation of the second laser pulse at $532 \mathrm{~nm}$ but not at $355 \mathrm{~nm}$ if the second laser pulse is delayed by $50 \mathrm{~ns}$. This is explained in terms of relaxation within the parent ion energy levels, the location of a low energy dissociation channel and the wavelengths of the lasers used. The main aspects of the fragmentation pattern are discussed in terms of the statistical theory of Rebentrost and Ben-Shaul.

Unlike electron impact mass spectrometry, which commonly uses either quasiequilibrium or RRKM theory to interpret fragmentation patterns, ${ }^{1}$ there appears to be no unifying theory which predicts multiphoton ionization-dissociation (MPID) mass spectral results. Instead, three mechanisms have been suggested which attempt to

$\dagger$ Part of this work was used in partial fulfillment of the Ph.D Degree of RSP and DAG.

$¥$ Present address: Department of Physics, Argonne National Laboratory, Argonne, IIl. 60439.

$\S$ Present address: Air Force Geophysics Laboratory, Hanscom Air Force Base, MA 01731. 
explain MPID mass spectra. ${ }^{1-7}$ Each mechanism tends to be more applicable in certain instances, depending upon the system under consideration and the frequency of excitation used.

In the first mechanism, the molecular ion is the precursor of all other ions. ${ }^{2}$ After the molecular ion is generated, it absorbs further photons to fragment into smaller ions which in turn absorb more photons etc. This is commonly referred to as the ionic ladder climbing mechanism and has been cited in numerous instances. ${ }^{2,5,6}$ In the second mechanism, the molecule fragments through low energy dissociation channels before ionization occurs. ${ }^{7}$ Therefore no common precursor intermediate exists for all observed ionic species. This mechanism has often been used to discuss the fragmentation behavior of organometallic systems. ${ }^{8,9}$ In the third mechanism the neutral molecule absorbs many more photons than are necessary to reach the lowest ionization potential before it does so. ${ }^{4}$ When it does, all observed species are simultaneously generated in one step and the entropic theory has been conveniently applied. ${ }^{10}$

Phenol has been the subject of numerous recent mass spectrometric investigations. ${ }^{11-14}$ Among the topics discussed has been the purported isomerization of the phenol radical cation to another structure prior to fragmentation. Several structures have been suggested. The sources of excitation used in all these reports include electron impact, field ionization collision induced dissociation and electron impact collision induced dissociation.

In this paper we have two sections. In the first, experimental results on the effect of laser power, laser wavelength, and repelling voltage using one or two pulsed lasers upon the fragmentation pattern of phenol are presented. In addition, results are given for the two-color experiment on the effect of the decay between the pulses. The results elucidate whether ionization or fragmentation is the primary process in the laser induced MPID of phenol.

As with other aromatic systems such as benzene, ${ }^{2}$ benzene- $d_{6},{ }^{15}$ and aniline, ${ }^{16}$ phenol is found to fragment via the ionic ladder climbing mechanism under $266 \mathrm{~nm}$ excitation. An interesting effect of the delay is observed and discussed.

In the second section of the paper, the Rebentrost-Ben-Shaul theoretical mechanism ${ }^{17}$ is used to qualitatively discuss the main results obtained. 


\section{EXPERIMENTAL STUDIES}

\section{Experimental}

The apparatus consists of a time-of-flight mass spectrometer designed for use with a multiphoton ionization source. More details of the apparatus are given elsewhere. ${ }^{15}$

The fourth harmonic $(266 \mathrm{~nm})$ of a Quanta-Ray DCR Nd:YAG laser is focussed with a $13 \mathrm{~cm}$ quartz lens into the ionization region of the mass spectrometer. The second $(532 \mathrm{~nm})$ or third $(355 \mathrm{~nm})$ harmonic is cofocussed through another $13 \mathrm{~cm}$ quartz lens into the ionization region along the same optical path as the $266 \mathrm{~nm}$ pulse but with different direction of propagation. Experiments have been carried out with the second and fourth harmonics simultaneously, with optical delays of 6,25 , and $50 \mathrm{~ns}$. Generally, the $266 \mathrm{~nm}$ fourth harmonic was generated with approximate energy of $0.1 \mathrm{~mJ} /$ pulse; the $532 \mathrm{~nm}$ second harmonic, and the $355 \mathrm{~nm}$ third harmonic were kept at approximately $5 \mathrm{~mJ} /$ pulse.

The repelling potential method used to elucidate the mechanism of multiphoton ionization dissociation is described in detail elsewhere. ${ }^{15}$ Briefly, two laser pulses separated in time by up to $50 \mathrm{~ns}$ are cofocussed at the entrance of a time-of-flight mass spectrometer. By varying the acceleration potential, it is possible to expose ions created by the first pulse to varying amounts of the second pulse. It is therefore possible to observe the evolution of ion signal due to fragmentation caused by the second pulse.

\section{Results and discussion}

Below we summarize and discuss the different experiments.

\section{A. The results of the $266 \mathrm{~nm}$ experiment}

1) Except for very low laser powers, significant amounts of $\mathrm{C}_{6} \mathrm{H}_{6} \mathrm{O}^{+}$ and $\mathrm{C}_{5} \mathrm{H}_{X}^{+}$are observed simultaneously (see bottom spectrum in Figure 1). This is in contrast to benzene ${ }^{2}$ and benzene- $d_{6}{ }^{15}$ where it is possible to produce exclusively the molecular ion in large quantities at moderate laser powers. This can be explained by the fact that the formation of $\mathrm{C}_{4} \mathrm{H}_{X}^{+}$, the lowest energy fragment of fewer than six 


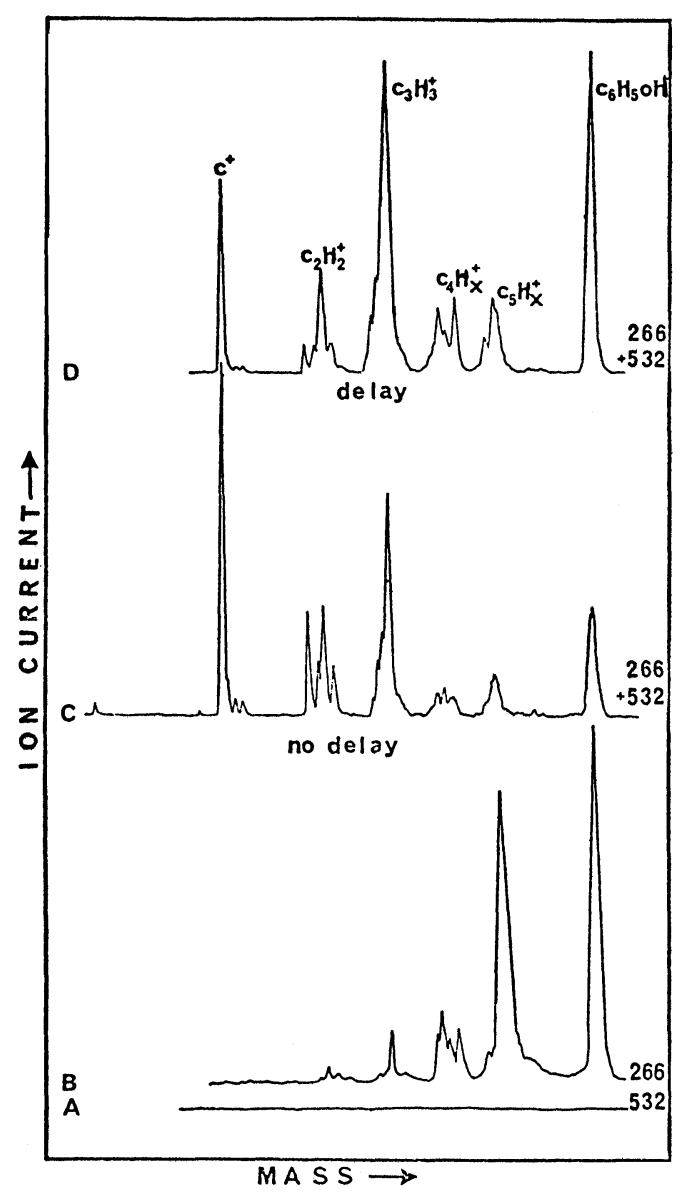

FIGURE 1 The effect of delay in two color experiments on the fragmentation pattern of phenol: (a) $532 \mathrm{~nm}$ alone showing that at the power used; ion formation is not possible by multiphoton processes. (b) $266 \mathrm{~nm}$ alone results in ion formation. (c) $266 \mathrm{~nm}+532 \mathrm{~nm}$ with no delay leading to parent destruction. (d) $266 \mathrm{~nm}+532 \mathrm{~nm}$ with $50 \mathrm{~ns}$ delay showing a relative protection of the parent.

carbon atoms from benzene, requires an excess of $5 \mathrm{eV}$ above the ionization continuum (i.e., a two photon process using $266 \mathrm{~nm}$ photons) ${ }^{18}$ whereas the formation of $\mathrm{C}_{5} \mathrm{H}_{6}^{+}$fragments from phenol requires only $3 \mathrm{eV}$ of energy (one $266 \mathrm{~nm}$ photon) above the ionization continuum. ${ }^{13}$ Thus, the difference in rate processes requiring 
one- and two-photon absorption might account for this observation.

2) Figure 2 shows that as the laser power increases, the parent ion yield relative to the total ion current decreases, while the $\mathrm{C}_{5} \mathrm{H}_{6}^{+}$and $\mathrm{C}_{3} \mathrm{H}_{3}^{+}$yields increase. This suggests that the $\mathrm{C}_{5} \mathrm{H}_{6}^{+}$species is derived from the molecular ion by the absorption of radiation. This together with the fact that it is formed with a high yield might suggest that the $\mathrm{C}_{5} \mathrm{H}_{X}^{+}$species is mostly $\mathrm{C}_{5} \mathrm{H}_{6}^{+}$.

\section{B. Two color experiments}

1. The effect of the delay (Figure 1).

The $532 \mathrm{~nm}$ laser pulse alone does not fragment the phenol molecular ion at the powers used in our experiments. However, as shown in Figure 1, in the presence of the $266 \mathrm{~nm}$ laser radiation, both the parent ion and the $\mathrm{C}_{5} \mathrm{H}_{X}^{+}$ions are found to decrease while the $\mathrm{C}_{3} \mathrm{H}_{X}^{+}, \mathrm{C}_{2} \mathrm{H}_{X}^{+}$, and $\mathrm{CH}_{X}^{+}$yields increase. This suggests that both the parent ion and the $\mathrm{C}_{5} \mathrm{H}_{X}^{+}$fragment formed by the $266 \mathrm{~nm}$ radiation absorb the $532 \mathrm{~nm}$ radiation to yield smaller ions. If the $532 \mathrm{~nm}$ radiation is delayed from the $266 \mathrm{~nm}$ pulse, it becomes inefficient at destroying the parent ion but continues to fragment the $\mathrm{C}_{5} \mathrm{H}_{X}^{+}$species (Figure 1d). This might suggest that fragmentation of the parent ion by the green laser pulse is possible from an excited level of the ion. The delay between the two laser pulses allows for the relaxation of ions to take place from this level to other levels or configurations from which the absorption of the green laser radiation has a much reduced one-photon transition probability.

Phenol has an intense absorption around $266 \mathrm{~nm}(4.66 \mathrm{eV})$. Because of this, and the relatively low value of its ionization potential $(8.37 \mathrm{eV} \text { as determined from its photoelectron spectrum })^{19}$ it is possible to reach the first excited electronic state of the phenol radical cation with a one-photon resonant, two-photon ionization process with the $266 \mathrm{~nm}$ radiation. Figure 3 shows an energy level diagram of phenol and its molecular ion. According to this diagram, two $266 \mathrm{~nm}$ photons excite phenol to the ${ }^{2} A_{2}$ level of the molecular ion. One green photon can energetically dissociate the molecular ion from this level to give $\mathrm{C}_{5} \mathrm{H}_{6}^{+}$and $\mathrm{CO}$. If however the ${ }^{2} A_{2}$ level of the parent ion could relax radiatively to the ground vibrational state of the ${ }^{2} B_{1}$ level of the ion or nonradiatively to an excited vibrational level of 


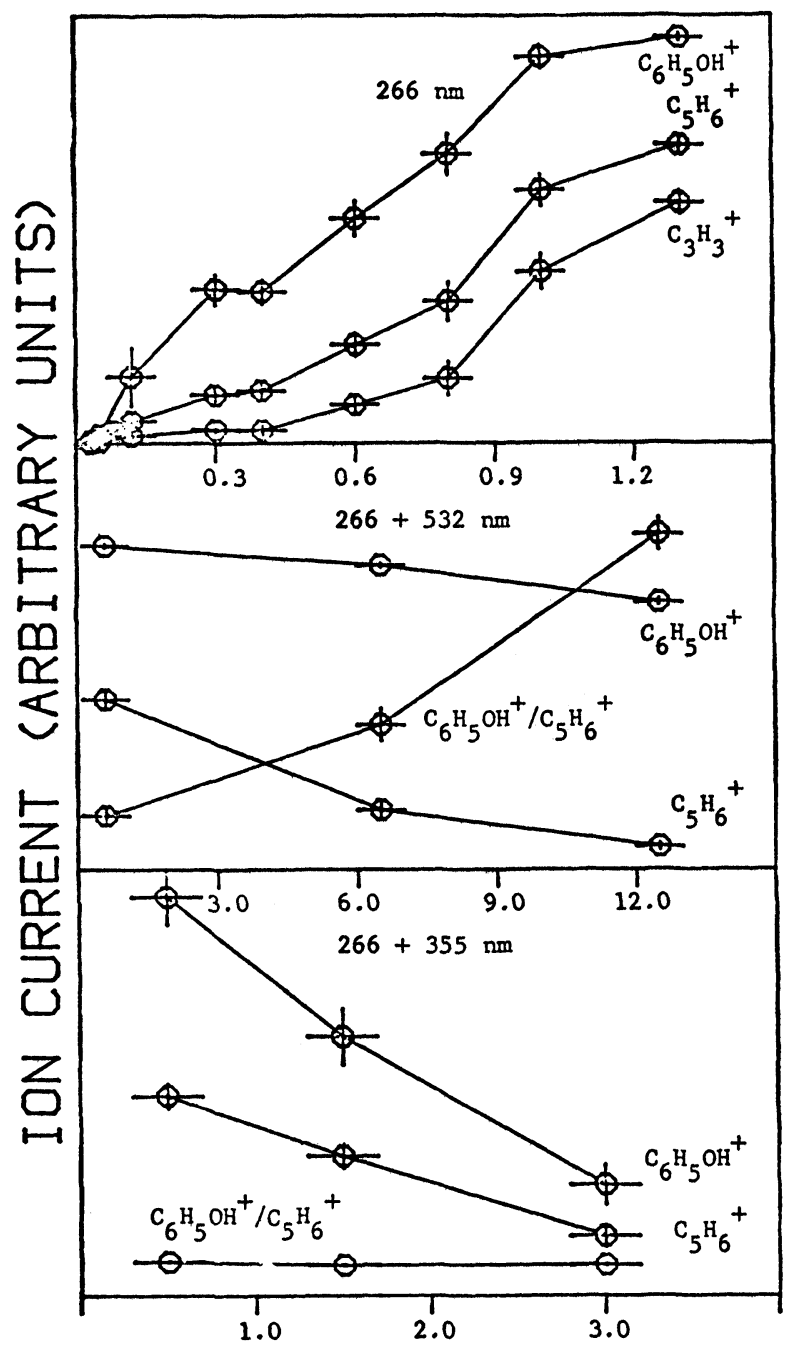

LASER INTENSITY (mJ/PULSE)

FIGURE 2 The effect of laser power on the fragmentation pattern. 


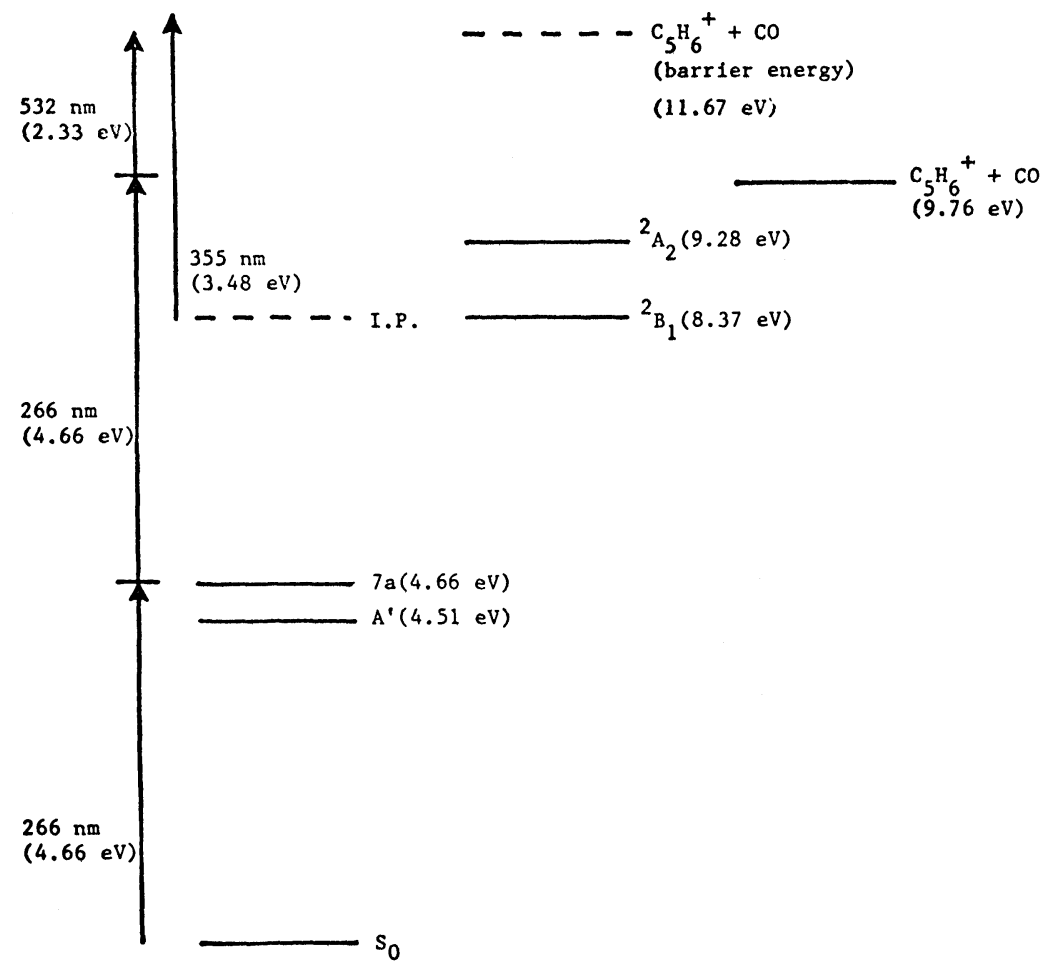

FIGURE 3 Partial energy level diagram of phenol and its cation together with the lowest energy channel-elimination of $\mathrm{CO}$ from the phenol cation. The energy of the photons of the different lasers used are shown with vertical arrows.

the ${ }^{2} B_{1}$ electronic state, a one photon absorption at $532 \mathrm{~nm}$ is either energetically insufficient to overcome the barrier to dissociation, or possesses a low absorption coefficient for the excited vibrational levels of the ${ }^{2} B_{1}$ state. One photon of the $355 \mathrm{~nm}$ radiation is capable of dissociating the ground vibrational state of the ion. Thus, if relaxation occurs to any of the vibrational levels of the ground electronic state, the ion might still have sufficient absorption coefficient that would make this wavelength efficient in fragmenting the molecular ion, even if it is delayed. This is shown in Figure 4. 


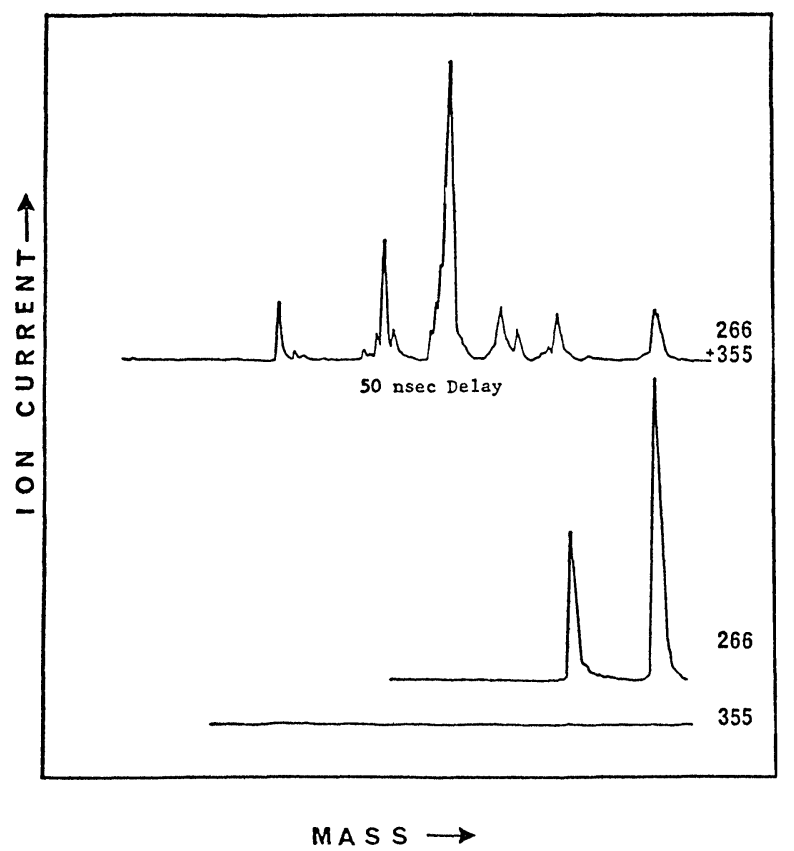

FIGURE 4 The effect of the delay of the $355 \mathrm{~nm}$ laser on the two color (266+ $355 \mathrm{~nm}$ ) fragmentation pattern. Unlike the $532 \mathrm{~nm}$ laser, the effect of delaying the $355 \mathrm{~nm}$ laser does not protect the parent ion destruction.

2. The contribution of neutrals.

Figure 5 shows that like benzene, further fragmentation with the $50 \mathrm{~ns}$ delayed $532 \mathrm{~nm}$ laser is found to diminish as the repelling voltage is increased (thus removing the parent and the $\mathrm{C}_{5} \mathrm{H}_{X}^{+}$ions formed from the first laser out of the focus of the delayed laser beam). This suggests that the contribution of neutral fragments formed from the first laser pulse to the formation of the small ionic fragments with the $532 \mathrm{~nm}$ pulse is not significant.

3. Power dependence.

The power dependence of the $532 \mathrm{~nm}$ and $355 \mathrm{~nm}$ radiation delayed for $50 \mathrm{~ns}$ from the $266 \mathrm{~nm}$ ionizing pulse is shown in Figure 2. The results are consistent with the above discussion. At the powers used 


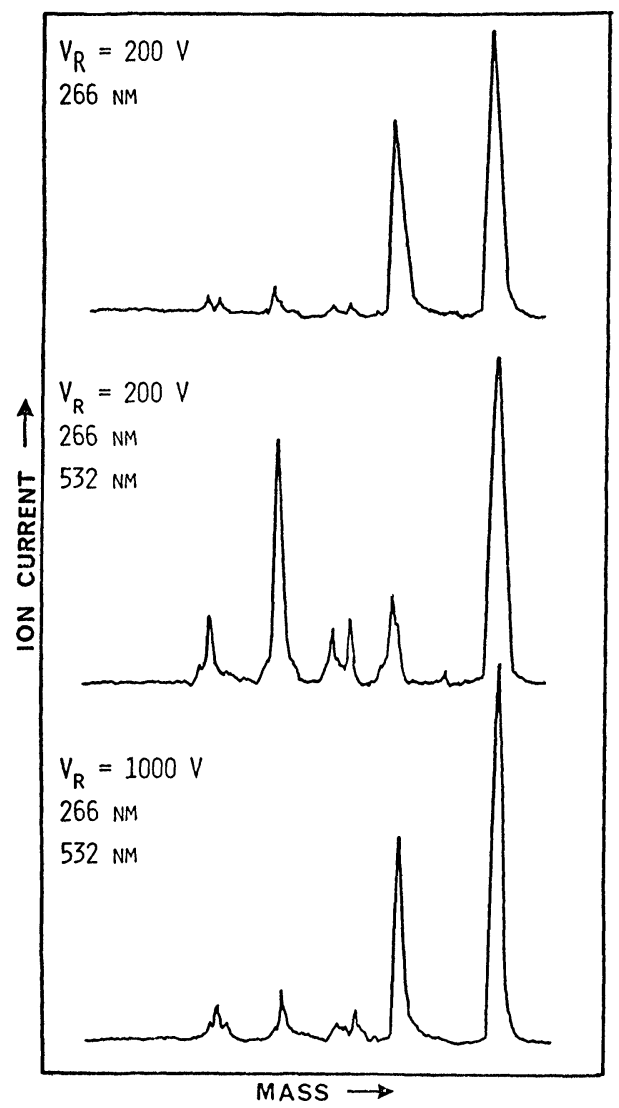

FIGURE 5 The effect of increasing the repelling potential in the $50 \mathrm{~ns}$ delayed two color $(266+532 \mathrm{~nm})$ experiment. The destruction of the primary pattern (formed from Hthe $266 \mathrm{~nm}$ radiation) with the $532 \mathrm{~nm}$ laser is found to be eliminated at high repelling voltage. This suggests a lack of neutral contribution to the ionic pattern from the $532 \mathrm{~nm}$ laser, as observed for benzene, aniline, and benzene- $d_{6}$.

of the $266 \mathrm{~nm}$ laser, the yield of the parent ion seems to be insensitive to the $532 \mathrm{~nm}$ power, but generally decreases with increasing the $355 \mathrm{~nm}$ power. The $\mathrm{C}_{5} \mathrm{H}_{X}^{+}$yields decrease continuously with the $532 \mathrm{~nm}$ power but increase first (due to the destruction of the parent ion), then decrease (due to its own destruction) as the power of the $355 \mathrm{~nm}$ radiation increases. 


\section{General observations and possible conclusions}

The results of the repelling voltage study (Figure 5) are consistent with the ladder climbing mechanism. That is, the molecular ion is the precursor of all other fragments. In contrast to similar experiments performed on benzene however, significant amounts of the daughter ion $\left(\mathrm{C}_{5} \mathrm{H}_{\mathbf{X}}^{+}\right)$are usually present. This is indicative of a low energy pathway (requiring in the case of $\mathrm{C}_{5} \mathrm{H}_{X}^{+}$one additional $532 \mathrm{~nm}$ photon) from the parent to daughter ion.

After delays of 6,25 , and $50 \mathrm{~ns}$, the parent ion is unaffected by the $532 \mathrm{~nm}$ radiation. We interpret this to mean that, during such time, the initially prepared first excited state of that ion decays to the ground electronic manifold by nonradiative processes from whose levels the absorption of $532 \mathrm{~nm}$ radiation has a very small one-photon transition probability. When the laser pulses are made coincident in time, absorption of the $532 \mathrm{~nm}$ photons may take place from the excited electronic level of the phenol radical cation leading to further climbing of the ionic ladder and leading to further dissociation.

When the $532 \mathrm{~nm}$ pulse was replaced with a $355 \mathrm{~nm}$ pulse, it becomes possible to dissociate the molecular ion directly from its ground electronic state, thus causing attenuation of the molecular ion signal even after delays are introduced.

In both delayed and non-delayed experiments, the $\mathrm{C}_{5} \mathrm{H}_{6}^{+}$radical cation absorbs at $532 \mathrm{~nm}$ and at $355 \mathrm{~nm}$ as is exemplified by its destruction at these wavelengths. Obviously, the extent and the specificity of ion destruction is sensitive to the power of the laser pulse, as well as its wavelength. This might open the field of determining the absorption spectrum of different ions by positive ion destruction spectroscopy.

The molecular ion of phenol displays a wavelength dependence to the second laser pulse. It is also sensitive to the delay between the first and the second pulse. When that pulse was the $532 \mathrm{~nm}$ second harmonic of the YAG, no destruction of the ion was observed with delay. On the other hand, delaying the $355 \mathrm{~nm}$ (third harmonic of the YAG) pulse is found to result in partial destruction of the molecular ion. As mentioned earlier, we interpret this as signifying that the $355 \mathrm{~nm}$ pulse might still be absorbed even if the delay causes a relaxation to any of the vibrational levels of the ${ }^{2} B_{1}$ electronic state. This might not be the case for the absorption of the $532 \mathrm{~nm}$ laser 
radiation. The observed lack of parent ion destruction at this wavelength if it is delayed from the ionizing pulse could be explained in terms of relaxation to excited vibrational levels of the ${ }^{2} B_{1}$ state from which absorption at this wavelength has a low probability. Therefore, at moderate laser powers no significant fragmentation is observed.

In both delayed and non-delayed experiments, the $\mathrm{C}_{3} \mathrm{H}_{X}^{+}$fragment cation is the predominant product of the destruction of $\mathrm{C}_{5} \mathrm{H}_{X}^{+}$under our experimental conditions of moderate laser power. This suggests that the second step in the dissociation of the phenol radical cation involves the elimination of acetylene $\left(\mathrm{C}_{2} \mathrm{H}_{2}\right)$. Under conditions of high laser power for the second laser pulse, $\mathrm{C}^{+}$is the predominant species observed.

\section{Conclusion}

The multiphoton ionization fragmentation mechanism of phenol arises from ionic ladder climbing. There are indications that the elimination of $\mathrm{CO}$ is the predominating first step in the fragmentation of the molecular ion. The resulting $\mathrm{C}_{5} \mathrm{H}_{X}^{+}$fragment is selectively destroyed (as compared to the parent ion) by exposure to a second laser with $532 \mathrm{~nm}$ photons, delayed on the $n s$ time scale from the initial ionizing laser pulse. This might suggest a means of determining the spectra of this positive ion by destruction spectroscopy.

The fragmentation of the parent ion by a second laser pulse is found to be diminished if a delay of $50 \mathrm{~ns}$ is used for the $532 \mathrm{~nm}$ pulse but not for the $355 \mathrm{~nm}$ pulse. An explanation invoking relaxation amongst the vibronic energy levels of the ion and a possible change in absorption cross section and a low energy dissociation channel yielding the $\mathrm{C}_{5} \mathrm{H}_{X}^{+}$species is given.

\section{MULTIPHOTON IONIZATION-DISSOCIATION OF PHENOL: A FURTHER TEST OF STATISTICAL THEORY}

Although many multiphoton ionization-dissociation experiments have been carried out, relatively little theoretical work has been attempted to better elucidate this fascinating observation in experimental chemical physics. The approach developed by Rebentrost and 
Ben-Shaul ${ }^{15}$ utilizes statistical methods to explain the multiphoton dissociation of benzene ion. Many different ionic species are produced in this experiment, necessitating the adoption of a simplified density of product-states treatment in the statistical calculations. Although this model reproduced well the benzene ion multiphoton-induced mass spectra, this system is probably not the most sensitive test of this model, owing to the large number of dissociation pathways, which might tend to wash out relatively small differences between statistical and non-statistical processes.

A better test of the model might be the phenol ion. The multiphoton ionization mass spectra of this species are simpler, even at high laser power, than the benzene spectra. This might be because there are several fragmentation pathways for phenol ion and its primary daughter fragment, $\mathrm{C}_{5} \mathrm{H}_{6}^{+}$, which lie at relatively low energy. These are:

$$
\begin{array}{ll}
\mathrm{C}_{6} \mathrm{H}_{6} \mathrm{O}^{+} \rightarrow \mathrm{C}_{5} \mathrm{H}_{6}^{+}+\mathrm{CO} & \Delta H=32.7 \mathrm{kcal} / \mathrm{mole} \\
\mathrm{C}_{5} \mathrm{H}_{6}^{+} \rightarrow \mathrm{C}_{3} \mathrm{H}_{3}^{+}+\mathrm{C}_{2} \mathrm{H}_{3} & \Delta H=65 \mathrm{kcal} / \mathrm{mole} \\
\mathrm{C}_{5} \mathrm{H}_{6}^{+} \rightarrow \mathrm{C}_{2} \mathrm{H}_{2}^{+}+\mathrm{C}_{3} \mathrm{H}_{4} & \Delta H=72.3 \mathrm{kcal} / \mathrm{mole}
\end{array}
$$

Therefore, the potential exists for a sensitive test of the RebentrostBen-Shaul method. In this section, the results of statistical calculations for this dissociation system are presented, and compared with experimental mass spectra of the phenol ion, given in Section 1.

\section{Equations and data for calculations}

For an ion $i^{+}$fragmenting to the species $j^{+}+n$, the Rebentrost-BenShaul model gives the unnormalized fragmentation probability ${ }^{17}$ as:

$$
\begin{aligned}
& P_{i j}\left(E_{i}, E_{j}\right) \\
& \quad=C_{t} \mu_{j n}^{3 / 2} \alpha_{i j} g_{j} g_{n} Q_{j} Q_{n} \frac{\left(E_{j}+a_{j} E_{0 j}\right)^{S_{i}+r_{j} / 2-1}\left(E_{n}+a_{n} E_{0 n}\right)^{S_{n}+r_{n} / 2+1 / 2}}{\Gamma\left(S_{j}+r_{j} / 2\right) \prod_{s_{j}} h \nu_{j} \Gamma\left(S_{n}+r_{n} / 2+3 / 2\right) \prod_{s_{n}} h \nu_{n}}
\end{aligned}
$$

where $C_{t}$ is a constant with units of (momentum) ${ }^{-3}, \mu_{j n}$ is the reduced mass of the $j^{+}-n$ pair, $\alpha_{i j}$ is the path degeneracy, $g_{j}$ and $g_{n}$ are electronic degeneracies, $Q_{j}$ and $Q_{n}$ are rotational factors given by:

$$
Q_{j}=\frac{1}{\sigma_{j}}\left(8 \pi^{2} / \hbar^{2}\right)^{r_{j} / 2} \pi^{1 / 2} \prod_{r_{j}} I_{j}^{1 / 2}
$$


$E_{j}, E_{i}$ and $E_{n}$ are energies of the respective species, related by the balance

$$
E_{i}-\Delta H_{i \rightarrow j}=E_{j}+E_{n}
$$

$a$ and $r$ are the number of vibrational and rotational degrees of freedom, the $a_{j} E_{0 j}$ terms represent zero-point vibrational energy (taken as zero in these calculations) and $\prod h \nu$ represents the product of all vibrational frequencies of species $j^{+}$and $n$. This expression is the internal energy distribution ion $j^{+}$.

When this expression is integrated over $E_{i}$, the total dissociation probability of $i^{-} \rightarrow j^{+}$is obtained. These integrals are of the form:

$$
\int_{0}^{a} d x x^{n / 2}(a-x)^{m / 2}=a^{n / 2+m / 2+1} \frac{\Gamma(n / 2+1) \Gamma(m / 2+1)}{\Gamma(n / 2+m / 2+2)}
$$

When this entire calculation is completed for all processes $i^{+} \rightarrow j^{+}$, $i^{+} \rightarrow k^{+}, i^{+} \rightarrow 1^{+}$etc, for a given $E_{i}$, branching ratios may then be directly taken.

The following dissociation processes were investigated. The data necessary to do calculations on these species are listed in Tables I and II.

\section{Results}

A. $\mathrm{C}_{6} \mathrm{H}_{6} \mathrm{O}^{+}$dissociation The process:

$$
\mathrm{C}_{6} \mathrm{H}_{6} \mathrm{O}^{+} \rightarrow \mathrm{C}_{5} \mathrm{H}_{6}^{+}+\mathrm{CO}
$$

has a $\Delta H$ of $32.7 \mathrm{kcal} / \mathrm{mol}$. All other dissociation processes lie considerably higher in energy. Indeed, the spectrum in Figure 5 (top) shows only $\mathrm{C}_{6}$ and $\mathrm{C}_{5}$ ions, probably making this the sole dissociation channel for $\mathrm{C}_{6} \mathrm{H}_{6} \mathrm{O}^{+}$in this experiment. However, some of the $\mathrm{C}_{4}$ ions appearing in the spectrum in Figure $1 \mathrm{~b}$ might actually be acrolein $\left(\mathrm{CH}_{2} \mathrm{CHCHO}\right)$ ions. Therefore, a rough calculation was performed for the process:

$$
\mathrm{C}_{6} \mathrm{H}_{6} \mathrm{O}^{+} \longrightarrow \mathrm{C}_{3} \mathrm{H}_{4} \mathrm{O}^{+}+\mathrm{C}_{3} \mathrm{H}_{2} \quad \Delta H=162 \pm 20 \% \mathrm{kcal} / \mathrm{mol}
$$

This process becomes roughly equal in probability to process (1) for $E_{i}=600 \mathrm{kcal} / \mathrm{mol}$, or six $266 \mathrm{~nm}$ photons, an unreasonably large energy deposition. 
TABLE I

Dissociation processes investigated in this study ${ }^{20}$

\begin{tabular}{|c|c|c|}
\hline \multirow[t]{2}{*}{$\mathrm{C}_{6} \mathrm{H}_{6} \mathrm{O}^{+}$} & $\longrightarrow \mathrm{C}_{5} \mathrm{H}_{6}^{+}+\mathrm{CO}$ & $\Delta H=32.7 \mathrm{kcal} / \mathrm{mol}$ \\
\hline & $\begin{array}{l}\longrightarrow \mathrm{C}_{3} \mathrm{H}_{4} \mathrm{O}^{+}+\mathrm{C}_{3} \mathrm{H}_{2} \\
\left(\mathrm{H}_{2} \mathrm{C}=\mathrm{CH}-\mathrm{CHO}^{+}\right)\end{array}$ & $162 \pm 20 \%$ \\
\hline \multirow[t]{8}{*}{$\mathrm{C}_{5} \mathrm{H}_{6}^{+}$} & $\begin{array}{l}\longrightarrow \mathrm{C}_{4} \mathrm{H}_{6}^{+}+\mathrm{C} \\
\left(\mathrm{H}_{2} \mathrm{C}=\mathrm{CHCH}=\mathrm{CH}_{2}^{+}\right)\end{array}$ & 177.3 \\
\hline & $\longrightarrow \mathrm{C}_{4} \mathrm{H}_{5}^{+}+\mathrm{CH}$ & 153.4 \\
\hline & $\begin{array}{l}\longrightarrow \mathrm{C}_{4} \mathrm{H}_{4}^{+}+\mathrm{CH}_{2} \\
\left(\Delta^{+}\right) \quad \text { (linear) }\end{array}$ & 142.7 \\
\hline & $\longrightarrow \mathrm{C}_{4} \mathrm{H}_{3}^{+}+\mathrm{CH}_{3}$ & 111.2 \\
\hline & $\begin{array}{l}\longrightarrow \mathrm{C}_{4} \mathrm{H}_{2}^{+}+\mathrm{CH}_{4} \\
\left(\mathrm{H}-\mathrm{C} \equiv \mathrm{C}-\mathrm{C} \equiv \mathrm{C}-\mathrm{H}^{+}\right) \quad \text { (linear) }\end{array}$ & 100.1 \\
\hline & $\underset{\left(\Delta^{+}\right)}{\longrightarrow}\left(\mathrm{C}_{3} \mathrm{H}_{3}^{+}+\mathrm{C}_{2} \mathrm{H}_{3}\right.$ & 65 \\
\hline & $\longrightarrow \mathrm{C}_{2} \mathrm{H}_{2}^{+}+\mathrm{C}_{3} \mathrm{H}_{4}$ & 72.3 \\
\hline & (linear) $\left(\mathrm{H}_{3} \mathrm{C}-\mathrm{C} \equiv \mathrm{CH}\right)$ & \\
\hline
\end{tabular}

TABLE II

Necessary data for dissociation species ${ }^{20}$

\begin{tabular}{lrrlc}
\hline & $\sigma$ & $g$ & \multicolumn{1}{c}{$I\left(\mathrm{~cm}^{-1}\right)$} & $(\Pi h \nu)^{1 / s}\left(\mathrm{~cm}^{-1}\right)$ \\
\hline $\mathrm{C}_{5} \mathrm{H}_{6}^{+}$ & 2 & 2 & $\sqrt{I_{a} I_{B} I_{c}}=0.118$ & 1230 \\
$\mathrm{C}_{4} \mathrm{H}_{6}^{+}$ & 1 & 2 & $1.37,0.1413,0.1413$ & 1180 \\
$\mathrm{C}_{4} \mathrm{H}_{5}^{+}$ & 1 & 2 & $1.37,0.2,0.2$ & 1150 \\
$\mathrm{C}_{4} \mathrm{H}_{4}^{+}$ & 2 & 2 & $1.00,0.15,0.13$ & 1143 \\
$\mathrm{C}_{4} \mathrm{H}_{3}^{+}$ & 2 & 1 & $9.5,0.15,0.15$ & 1078 \\
$\mathrm{C}_{4} \mathrm{H}_{2}^{+}$ & 4 & 6 & $0.14,0.14$ & 812 \\
$\mathrm{C}_{3} \mathrm{H}_{3}^{+}$ & 6 & 1 & $1.0,1.0,0.5$ & 1252 \\
$\mathrm{C}_{2} \mathrm{H}_{2}^{+}$ & 2 & 4 & $1.15,1.15$ & 1225 \\
$\mathrm{C}_{3} \mathrm{H}_{4} \mathrm{O}^{+}$ & 1 & 2 & $\sqrt{I_{a} I_{B} I_{c}}=0.186$ & 1130 \\
$\mathrm{C}_{3} \mathrm{H}_{4}$ & 3 & 2 & $5.21,0.285,0.285$ & 1238 \\
$\mathrm{C}_{3} \mathrm{H}_{2}$ & 2 & 2 & $\sqrt{I_{a} I_{B} I_{c}}=0.25$ & 1211 \\
$\mathrm{C}_{2} \mathrm{H}_{3}$ & 2 & 2 & $9.0,1.06,0.95$ & 1586 \\
$\mathrm{CH}_{4}$ & 12 & 1 & $5.2412,5.2412,5.2412$ & 1957 \\
$\mathrm{CH}_{3}$ & 6 & 2 & $9.6,4.8,4.8$ & 2072 \\
$\mathrm{CH}_{2}$ & 2 & 3 & $7.9,7.9$ & 2049 \\
$\mathrm{CH}$ & 1 & 4 & $14.5,14.5$ & 2858 \\
$\mathrm{CO}$ & 1 & 1 & $1.93,1.93$ & 2170 \\
$\mathrm{C}$ & 1 & 9 & - & - \\
\hline
\end{tabular}


B. $C_{5} H_{6}^{+}$Dissociation to $C_{4}^{+}$Species For $E_{i}=214 \mathrm{kcal} / \mathrm{mol}$ (four $532 \mathrm{~nm}$ photons), the probabilities for each of these dissociation processes increases as the $\Delta H$ for the processes decrease, which might be expected. However, none of these $\mathrm{C}_{4}$ species appears for certain in the experimental spectra. Even for $E_{i}=250 \mathrm{kcal} / \mathrm{mol}$, the probability of the most probable $\mathrm{C}_{5}^{+} \rightarrow \mathrm{C}_{4}^{+}$process is calculated to be 200-300 times smaller than the least probable $\mathrm{C}_{5}^{+} \rightarrow \mathrm{C}_{3}^{+}+\mathrm{C}_{2}$ process. Higher levels of energy deposition are improbable. Therefore, $\mathrm{C}_{5}^{+} \rightarrow \mathrm{C}_{4}^{+}$ processes appear to be unimportant in this experiment.

C. $C_{5}^{+} \rightarrow C_{3}^{+}+C_{2}$ The species $\mathrm{C}_{3} \mathrm{H}_{3}^{+}$and $\mathrm{C}_{2} \mathrm{H}_{2}^{+}$appear prominently in the experimental mass spectra. While the $\mathrm{C}_{3} \mathrm{H}_{3}^{+} / \mathrm{C}_{2} \mathrm{H}_{2}^{+}$ratio varies to some degree, probably because of differing laser powers between the spectra, the value is around four in Figure 1c. Accordingly, calculations were performed for varying $E_{i}$. The value of $E_{i}$ producing a branching ratio of four was found to be $190-195 \mathrm{kcal} / \mathrm{mol}$ (Figure 6).

The internal energy distribution for $\mathrm{C}_{5} \mathrm{H}_{6}^{+}$formed from phenol ion is plotted in Figure 7 for total absorbed photon energy of $3 \times 266 \mathrm{~nm}$. $E\left(p_{\max }\right)$ is at $88.5 \mathrm{kcal} / \mathrm{mol}$.

\section{Discussion}

The statistical theory calculations correctly predict the relative absence of ions other than $\mathrm{C}_{6} \mathrm{H}_{6} \mathrm{O}^{+}$and $\mathrm{C}_{5} \mathrm{H}_{6}^{+}$at low laser powers. Some $266 \mathrm{~nm}$ single-beam spectra show a few other ions at lower masses, but this is most probably due to $\mathrm{C}_{5} \mathrm{H}_{6}^{+}$dissociation. Of course, this is not a sensitive test of the theory. Since the threshold for $\mathrm{C}_{6} \mathrm{H}_{6} \mathrm{O}^{+} \rightarrow \mathrm{C}_{5} \mathrm{H}_{6}^{+}+\mathrm{CO}$ is so much lower (at least $70 \mathrm{kcal} / \mathrm{mol}$ ) than the other $\mathrm{C}_{6} \mathrm{H}_{6} \mathrm{O}^{+}$dissociation processes, one might expect this channel to be the only one operative even if statistical theory did not apply here. In all probability, it does not apply, since $\mathrm{CO}$ abstraction from $\mathrm{C}_{6} \mathrm{H}_{6} \mathrm{O}^{+}$is not a simple bond scission.

The statistical calculations also are in accord with the apparent absence of a series of $\mathrm{C}_{4} \mathrm{H}_{n}^{+}$species arising from $\mathrm{C}_{5} \mathrm{H}_{6}^{+}$. On the other hand, it is not possible to explain with this theory the dual peaks in the $C_{4}$ region observed in the experimental mass spectra. In order to understand the $\mathrm{C}_{4}$ region better, it is necessary to accurately assign 


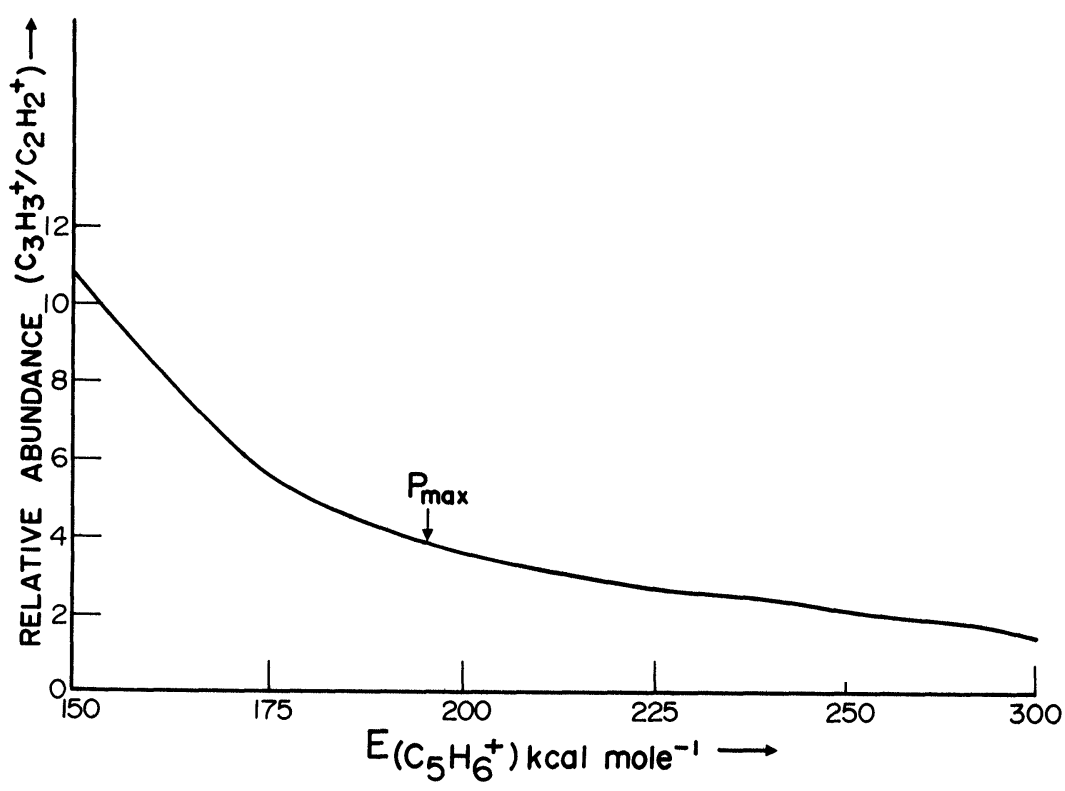

FIGURE 6 The $\left(\mathrm{C}_{3} \mathrm{H}_{3}^{+}\right) /\left(\mathrm{C}_{2} \mathrm{H}_{2}^{+}\right)$ionic ratio as a function of the internal energy of $\mathrm{C}_{5} \mathrm{H}_{6}^{+}$. The observed ratio in Figure $1 \mathrm{c}(\sim 4)$, requires $\sim 190 \mathrm{kcal} / \mathrm{mol}$ (i.e., by penol absorbing $3 \times 266 \mathrm{~nm}$ photons to form $\mathrm{C}_{5} \mathrm{H}_{6}^{+}$followed by two $532 \mathrm{~nm}$ photons to create these two ions).

the masses of these two peaks. In any event, it appears that a non-statistical constraint operates to produce this pair of peaks.

However, the statistical theory proves very useful for explaining the $\mathrm{C}_{3} \mathrm{H}_{3}^{+} / \mathrm{C}_{2} \mathrm{H}_{2}^{+}$ratio produced from $\mathrm{C}_{5} \mathrm{H}_{6}^{+}$dissociation. A consideration of the photon usage in the $266 \mathrm{~nm}$ single-beam experiment is enlightening here. Two $266 \mathrm{~nm}$ photons supply $9.32 \mathrm{eV}$. The ionization potential of phenol is $8.37 \mathrm{eV}$. This leaves $0.95 \mathrm{eV}$ or $22 \mathrm{kcal} / \mathrm{mol}$ to cause dissociation of $\mathrm{C}_{6} \mathrm{H}_{6} \mathrm{O}^{+}$, which is less than the $32.7 \mathrm{kcal}$ required for the $\mathrm{C}_{5} \mathrm{H}_{6}^{+}+\mathrm{CO}$ channel. Therefore, further $266 \mathrm{~nm}$ photon absorption is required to cause dissociation. One further $266 \mathrm{~nm}$ photon supplies $107 \mathrm{kcal} / \mathrm{mol}$. Then the maximum possible energy which could be present in $\mathrm{C}_{5} \mathrm{H}_{6}^{+}$is $107+22-32.7=$ $96.3 \mathrm{kcal} / \mathrm{mol}$. The energy distribution of $\mathrm{C}_{5} \mathrm{H}_{6}^{+}$calculated from the statistical theory shows $E\left(p_{\max }\right)=88.5 \mathrm{kcal} / \mathrm{mol}$, with $>90 \%$ of the $\mathrm{C}_{5} \mathrm{H}_{6}^{+}$ions having higher energy than the threshold for $\mathrm{C}_{5} \mathrm{H}_{6}^{+} \rightarrow \mathrm{C}_{2} \mathrm{H}_{2}^{+}+\mathrm{C}_{3} \mathrm{H}_{4}, \Delta H=72.3 \mathrm{kcal} / \mathrm{mol}$. However, most $\mathrm{C}_{5} \mathrm{H}_{6}^{+}$ 


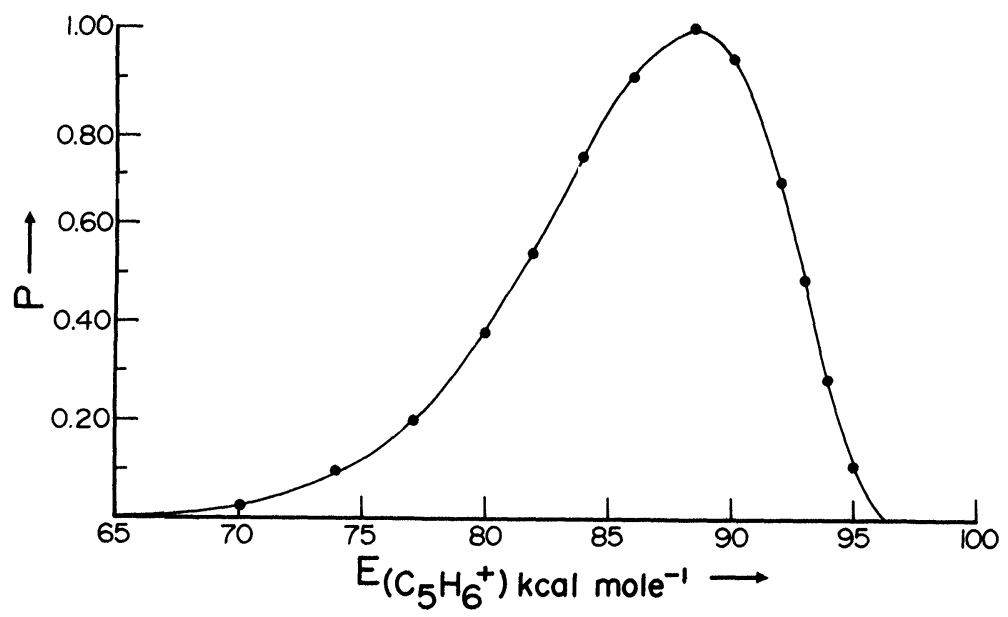

FIGURE 7 The internal energy distribution for the $\mathrm{C}_{5} \mathrm{H}_{6}^{+}$formed from phenol ion as a function of the total absorbed energy of $3 \times 266 \mathrm{~nm}$ photons. The figure shows that the statistical theory predicts that the most probable internal energy of $\mathrm{C}_{5} \mathrm{H}_{6}^{+}$is $88.5 \mathrm{kcal} / \mathrm{mol}$.

ions are not dissociated to smaller species, even though the threshold energy has been exceeded. Clearly, most $\mathrm{C}_{5} \mathrm{H}_{6}^{+}$ions are metastable on a time scale of this experiment $(1 \mu \mathrm{s})$.

However, a total energy deposition of $3 \times 266 \mathrm{~nm}$ photons is insufficient to create the observed $\mathrm{C}_{3} \mathrm{H}_{3}^{+} / \mathrm{C}_{2} \mathrm{H}_{2}^{+}$branching ratio of four in the calculation. Approximately $100 \mathrm{kcal} / \mathrm{mol}(1 \times 266 \mathrm{~nm}$, $2 \times 532 \mathrm{~nm})$ additional energy above $E\left(p_{\max }\right)=88.5 \mathrm{kcal} / \mathrm{mol}$ is necessary. Therefore, we believe that for those dual-beam spectra with a $\mathrm{C}_{3} \mathrm{H}_{3}^{+} / \mathrm{C}_{2} \mathrm{H}_{2}^{+}$ratio of four, three $266 \mathrm{~nm}$ photons are absorbed to create $\mathrm{CO}$ and $\mathrm{C}_{5} \mathrm{H}_{6}^{+}$which then absorbs two additional green photons to create $\mathrm{C}_{3} \mathrm{H}_{3}^{+}$and $\mathrm{C}_{2} \mathrm{H}_{2}^{+}$. In this case, the statistical theory provides a natural and reasonable explanation for the experimental mass spectra, although this does not constitute absolute proof of its validity.

\section{Summary}

There appear to be certain aspects of multiphoton dissociation of $\mathrm{C}_{6} \mathrm{H}_{6} \mathrm{O}^{+}$which may be explained by the Rebentrost-Ben-Shaul 
theory. Specifically, the theory explains the $\mathrm{C}_{3} \mathrm{H}_{3}^{+} / \mathrm{C}_{2} \mathrm{H}_{2}^{+}$branching ratio arising from $\mathrm{C}_{5} \mathrm{H}_{6}^{+}$dissociation. On the other hand, it gives little information about the initial dissociation of $\mathrm{C}_{6} \mathrm{H}_{6} \mathrm{O}^{+}$, and appears to be inconsistent with the experimental results in the $\mathrm{C}_{4}$ region. In any event, this is a promising system on which to carry out experiments in order to establish whether this theory works in this case, since the mass spectra are relatively simple except at very high powers, making it easier to reject certain dissociation pathways. This research is now in progress. ${ }^{21}$

\section{Acknowledgement}

We wish to thank the National Science Foundation for their financial support.

\section{References}

1. J. C. Lorquet, Org. Mass Spectrom. 16, 469, (1981).

2. U. Boesl, J. J. Neusser and E. W. Schlag, J. Chem. Phys. 72, 4327, (1980).

3. V. S. Antonov and V. S. Letokhov Appl. Phys. 24, 89, (1981).

4. P. Lambropoulos, Applied Optics 19, 3926, (1980).

5. J. P. Reilly and K. L. Kompa, J. Chem. Phys. 73, 5468, (1980).

6. D. H. Parker, R. B. Bernstein and D. A. Lichtin, J. Chem. Phys. 75, 2577, (1981).

7. For a recent concise discussion see: A. Gedanken, M. B. Robin and N. A. Kuebler, J. Phys. Chem. 86, 4096, (1982).

8. D. P. Gerrity, L. J. Rothberg and V. Vaida, Chem. Phys Lett. 74, 1 (1980).

9. G. J. Fisanick, A. Gedanken, T. S. Eichelberger, N. A. Kuebler and M. B. Robin, J. Chem. Phys. 75, 5215; (1981).

10. J. Silberstein and R. D. Levine, Chem. Phys. Lett. 74, 6, (1980).

11. (a) D. H. Russell, M. L. Gross, J. Van der Greef and N. M. M. Nibbering, Org. Mass Spectrom. 14, 474 (1979); (b) D. H. Russell, M. L. Gross and N. M. M. Nibbering, J. Am. Chem. Soc. 100, 6133, (1978).

12. F. Borchers, K. Levson, C. B. Theissling and N. M. M. Nibbering, Org. Mass Spectrom. 14, 474, (1977).

13. A. Maquestiau, Y. V. Van Haverbeke, R. Flammang, C. De Meyes, K. B. Das, and G. S. Reddy, Org. Mass Spectrom. 12, 631, (1977).

14. H. J. Walther, H. Eyer, U. P. Schlunegger, C. J. Porter, E. A. Larka and J. H. Beynon, Org. Mass Spectrom. 17, 81, (1982).

15. R. S. Pandolf, D. A. Gobeli and M. A. El-Sayed, J. Phys. Chem. 85, 1779, (1981).

16. D. Proch, D. M. Rider and R. N. Zare, Chem. Phys. Lett. 81, 430, (1981).

17. F. Rebentrost and A. Ben-Shaul, J. Chem. Phys. 74, 3255 (1981).

18. J. L. Franklin, J. G. Dillard, H. M. Rosenstock, J. T. Herron, K. Draxl and F. H. Field, Natl. Stand. Ref. Data Ser. Natl. Bur. Stand. 26, (1969).

19. T. P. Debies and J. W. Rabalais, J. Electron Spectrosc. 1, 83, (1972). 
20. Data for calculations were taken from Ref. 17 and the following sources: H. M. Rosenstock, K. Draxl, B. W. Steiner and J. T. Herron, J. Phys. Chem. Ref. Data 6, Suppl. 1 (1977); G. Herzberg, Molecular Spectra and Molecular Structure, Vols. I-III (Van Nostrand, New York 1958); S. W. Benson, Thermochemical Kinetics: Methods for the Estimation of Thermochemical Data and Rate Parameters (John Wiley \& Sons, New York, 1976); F. Rebentrost and A. Ben-Shaul, FORTRAN computer program forming basis for Ref. 17.

21. Jeng-Jiun Yang, F. Rebentrost and M. A. El-Sayed, in preparation. 